\title{
What is in a name? A Short Survey on the Sources and the Factors Affecting the Act of Name-Giving
}

\author{
Abbas Eslami-Rasekh \\ Ph.D. in TEFL - University of Isfahan, Iran \\ Emil: abbasseslamirasekh@yahoo.com \\ Mohammad Ahmadvand \\ Ph.D. Candidate - University of Isfahan, Iran \\ Email: mohammad_ahmadvand2010@yahoo.com
}

Accepted: July 04, 2012 Published: August 10, 2012

Doi:10.5296/jsr.v3i2.2127ＵRL: http://dx.doi.org/10.5296/jsr.v3i2.2127

\begin{abstract}
Today, nations are not only transferring goods, services, knowledge, and technologies but also cultures and values which may be points of conflict especially in multicultural societies. This entails creating understanding among nations, people, and ethnic groups through intercultural communication studies and research. An area of interest for many people, lay or expert, is the practice of name-giving; it is more than just an act of designation or an official registration. Names are expressions of cultural identity deeply imbedded in sociocultural contexts showing the underlying values and practices of people in an area. This paper aims at surveying and the factors, motives, and the reasons of name-giving patterns and classifying the sources based on which people choose names for their children. On the whole, fourteen common classes of sources and a short description of their subdivisions will be presented in the paper.
\end{abstract}

Keywords: name-giving, cultures, values and beliefs, cultural identity, ethnic groups

\section{Introduction}

Rapid development of international trade, the improvement of communication technologies, the ease of access to means of transportation and the progress in globalization have increased the capacity for local as well as international interaction among people (Wang and Le, 2011). These changes and the outcomes of globalization add new concepts to the literature of various disciplines one of which is intercultural communication competence (Penbek, et al, 
2009). Today, the world is considered as a village in which coping with differences both at home and abroad is an important issue to be considered. Differences in values, attitudes, ethnicity, social practices, religion, etc. must be fully respected and integrated into our lives. Intercultural communication failure both at the local and the international levels can lead to intercultural maladjustment, misunderstanding, and even cultural shock. One of the causes of this failure is the lack of adequate knowledge and skills to communicate with others from other cultures (Wang and Le, 2011). Intercultural communication competence considered to be a sub-skill of communication competence (Deardorrff, 2004) gives people the ability to change their attitude and behavior toward others and to be open and flexible to other cultures. It is a critical issue for individuals to survive in the globalized societies of this century. Language is an intrinsic part of our everyday reality and we put our linguistic knowledge to use to give shape to our internal thoughts (Widdowson, 2007). People negotiate, realize, or even reject identities through the use of language, a factor for expressing identity stronger than cultural artifacts such as dress, food, housing, etc. (Wardhaugh, 2006). Our knowledge of the world and our experiences of social events and social realities influence our interpretations of individual words; even the use of personal pronouns can be an indicator of identity (Bloor and Bloor, 2007). Human cognition and human experience are closely related to humans' use of language (Johnstone, 2008). An important manifestation of language is naming. Names not only function as common and rigid devices for direct reference but also function as abstract linguistic markers that signal and reinforce the referents' individuality (Jeshion, 2009). Personal names occur in all languages forming a special group within the vocabulary of languages; like any other word, they follow the phonological, morphological, syntactic, and semantic rules of the language.

Naming is a specific linguistic act which shows values, traditions, hopes, fears, and everyday events in people's lives; names reveal the preferences and concerns of their owners as well as givers in terms of real life objects, actions, and beliefs (Rosenhouse, 2002) Name is people's possession and identification telling the world who they are (Mayrand, 2011).

A given name _also known as the first name, forename, and in Christian countries as the Christian name_ is a personal name that differentiates between members of a family or a society. A given name is purposefully given to a child by parents, grandparents, godfathers, local clergymen, etc. before or after the birth, unlike the family name which is an inherited and hence predetermined one (Wikipedia, 2011). The given names come before the family name in most European cultures, and after the family name in Hungary, parts of Africa, and most of the East Asia (e.g. China, Japan, Korea, and Vietnam). Some people have more than one forename but usually one is the main forename. Parents invest tremendous effort in choosing the name of their children which shows the importance of names. The name of a child is important for a child's earliest sense of identity and may affect his/her feeling for a lifetime; it helps define a child within the family, to friends, and to the outsiders (Wikipedia, 2011; Aden, 2011).

\section{The Significance of Studying Names}


Names give us important insights because they can act as an indicator of the patterns of social and cultural organization of societies. They render important information about the sex and the infant's social class and some background information about the name-giver; names may reveal important information about the social and historical circumstances at the time of the birth of a child. They also exercise a great symbolic power because names are chosen consciously and by free will and even with a lot of considerations and care. Names identify a person and may send a message to others regarding the name-givers' hopes, prayers, cultural traditions, religious background, etc. (Alford, 1987). Naming is not just a simple act of designation or an official registration of a name for paper work; a name grants identity to and even develops or establishes the personality of a person. Naming is not a simple phenomenon; it is a clear expression of cultural identity deeply imbedded in sociocultural contexts (Encyclopedia of Children, 2011). A given name serves as an identity marker both for the child in his/her future activities and for recognition by others (Gerhards and Hans, 2009). Implicitly shared conventions and traditions adhered to by people constitute the identity of a nation or group; these conventions make actions and transactions and on the whole the internal functioning of a culture possible.

Knowledge of naming practices can even help us trace our families back to their origins, for example, a village, tell us about their jobs and activities, or even tell us how our ancestors looked like physically (Myrand, 2011). A historical study of names can help us access the past because they are reflections of our ancestors' everyday life, their world views, and family relationships and beyond. Names have an integrative function too; they integrate the new baby into the family organization or the community he will be a member of and grow up in (Encyclopedia of Children, 2011). Gudrun (2002), for example, reports that most Icelandic personal names are of Nordic origin, many of them are found in sagas, and some can be traced back to the Christianization of the country in the year 1000. Many things can act as an identity marker, for example, type of housing, clothes, the way we talk, our car, etc. but names are chosen freely and without any financial cost, or investment of time and effort; as such, they are pure expressions of parents' preferences and ideas (Liberson, 2009).

Personal names reveal interesting details about people's life, their origins, professions, traditions, fashion, social rank, etc (Ghaleb Al-Zumor, 2009). Toppe (2011) reported of seventy percent of the Norwegian names being related to farms. Bryner (2010) comments on these days' spread of unusual names believing this shows the parents' overall philosophy that their own child is special, that having a unique name helps the child to be salient and to stand out, that fitting into social norms is something to be avoided, and that names can lead the child towards the parents' desired personality traits. For instance, in Christian countries 'Jesus' is not used for boys but 'Mary' is used for girls showing people's belief that Jesus is considered taboo or sacrilegious in parts of the Christian world (Wikipedia, 2011).

There are also interesting cases of the real effect and use of names in people's everyday activities. In Lithuania, (Girvilas, 1978) people believe that names can determines or even 
change a child's destiny. People in some parts of the world even consider names in deciding their future practices like marriage. In Burma, as an instance, the initial of a child's name is consistent with the day on which the child is born; some days are believed to be incompatible with each other, so people born on these days cannot marry together and, for example, you can't find a K-husband with an H-wife (Medlej (2011). In Korea we can see the same case as Koreans avoid marrying people who have the same family name. For example, marriage between the Kims and the Parks, which are two very common last names in Korea, is considered to cause problems. There are interesting cases of the relationship between naming and religion reported too. In Judaism it is a common practice to choose sectarian or theophorous names for men, in Christianity for women, and Islam for both in. In France, during1830s and 1840s, priests gave the name Philomene _after Saint Philomena who was associated with virginity_ to illegitimate girls, thereby marking their status (Encyclopedia of Children, 2011).

Social considerations are also closely tied to naming practices. Naming a child after godparents also shows the kind of social relations and the social structure in a society; parents create new social relationships, create and reinforce social networks, and seek alliances through godparent patronage (Encyclopedia of Children, 2011). In a study (Gardner, 1988), it was shown that in Arab countries traditional names refer to virtues of piety, justice, abundance, and purity, and enduring names, that is, names which have retained their popularity encompass concepts of companionship and kindness; in these countries, new names used by people depict concepts of love, happiness, and hope. Sue and Telles (2007) argue that traditional or ethnic names are more frequently used for boys because they are expected to carry on family name, reputation, and traditions.

\section{Changes in Name-Giving Practices}

Another important aspect of studying personal names and name-giving is looking for changes in naming practices of different nations or ethnic groups. Convergence into or divergence from other ethnic groups, whether they are minority or the dominant groups, could arise from spatial, economic, occupational, or social segregation, or conversely because of acculturation, willingness for integration, having a kind of instrumental motivation, etc. These changes are reflected in people's everyday life, their musical taste, the colour and the design of their dresses, religion and religious practices, recreational activities, and name-giving practices (Gordon, 1964). A study of changes in name-giving among different nations may show forced acculturation, like the time when, in 1986, the Bulgarian government forced the Turkish minority to adopt Slavic names, or like the time when the Turkish constitution in Turkey banned the use and registration of Kurdish names from 1983 to 2000, forced segregation, which happened when in 1938 Jews were forced to use only Jewish names to make their Jewish origin distinguishable by adding 'Israel' and 'Sara' to the names of men and women respectively, voluntary acculturation, which happens, for example, when ethnic groups voluntarily give up their traditional first names and adopt names of the dominant ethnic group without any force by law or other social forces, and voluntary ethnic segregation or 
maintenance, for which we have the case of the French Revolution of 1789 after which people turned back to names derived from the ancient Roman tradition (Gerhrads and Hans, 2009).

There are some studies reporting interesting cases of the reasons of changes in names around the world. These days it is becoming a common practice to name children after real or even fictional figures and characters from novels, opera heroes, actors and actresses, musicians, singers, sportsmen, famous businessmen, etc. In 2004, the names 'Keira' and 'Kiera' gained popularity in United Kingdom, because the British actress 'Keira Knightley' was at the peak of fame at that time. The song "Hey Jude", released by the Beatles, increased the frequency of the name 'Jude' chosen for children. Likewise, after the popularity of the film 'Home Alone', there appeared a great interest in adopting the name 'Kevin', the main character of the film (Wikipedia, 2011.; Encyclopedia of Children, 2011). When the civil war finished, African Americans returned back to names like Moses and Abraham which the black were banned from choosing; they also started to use the complete names like Thomas instead of shortened names like Tom and freely adopted names which showed their African origin (Conrad, 2001). Gardner (1992, and 1993), considering the traditional role for boys in Arab societies, believes the reason that girls outnumber boys in adopting new names is because boys are supposed to continue the traditions and the good family name; on the other hand, girls are given new names to enhance their attractiveness, this change suggesting change for a better future. Regarding the effect of religion on name-giving, we can mention certain Hadiths (words of wisdom by the Prophet Mohammad and Imams) and Quranic verses which include recommendations regarding the characteristics of names chosen for boys. In Egypt, soap opera singers' popularity caused the emergence of new names in the Arab world.

Personal names exist, change, develop, and die; this is what happens in all languages. The study of name-giving and changes in name-giving practices of different nations and ethnic groups show us interesting patterns in a community's culture; sometimes changes in these patterns reveal the presence of a certain spirit among certain people during a certain time (Bryner, 2010; Ghaleb Al-Zumor, 2009).

\section{Sources of Names}

Personal names may be derived from different sources and because of different factors and motives. The following list includes the most common sources reported in the literature (Myrand, 2011; Wikipedia, 2011; Encyclopedia of Children, 2011; Conrad, 2011; Ghaleb Al-Zumor, 2009; Djcnonyomaye, 2002):

\subsection{Names Of Motherland}

These names can be the name of the city, province, or the country the child belongs to, generic names meaning homeland, names of races, or names of tribes. 


\subsection{Personal Features}

These features may concern the external/physical or internal/spiritual features, which in turn can be positive or negative.

\subsection{Occupations}

This category includes the jobs or even the tools necessary for doing a job.

\subsection{The Time Of Birth}

This can be the name of the day of the birth, the moment or part of the day when the child is born, or the circumstance of the birth, for example, the festivals or celebrations at the time of the birth of the child.

\subsection{Objects Around}

People usually choose the name of objects which are of high importance in their lives.

\subsection{Traditions Or Local Customs}

Children may be given the name of everyday chores, festive customs and activities, objects used in ceremonies, cultural or ethnic concepts, musical traditions, and traditional literary works which are honoured nationwide.

\subsection{Variations Of Another Name}

People, for instance, may change a male name to a female name by adding a suffix to the male name or vice versa.

\subsection{Geographical Places}

These can be both common generic names and proper names like the name of specific cities, villages, mountains, rivers, and plains.

\subsection{Names Of Important People}

These names could include real names of religious or divine, political, artistic, or historical characters or even fictional names in history, myth, and literature. 


\subsection{Names Of Ancestors}

Children may be given the name of their ancestors or patronymic names or even their fathers, especially if they are dead.

\subsection{Names Based On Nature}

This category includes various subdivisions such rain or snow, natural phenomena, seasons, natural objects, weather conditions, common names of animals, the agricultural environment, common names of plants, and the sounds present in nature.

\subsection{Brands}

These may be the names of famous commercial brands and goods, especially luxurious ones.

\subsection{Harmony Of Names}

Sometimes parents who have more than one child try to choose names which are sound-harmonious.

\subsection{Innovation Names}

Sometimes parents devise unique names to make their children salient. These names may be names which are not chosen by other people at all or for example may be names derived from abbreviations of another name or even derived from the combination of other names.

\section{Conclusion}

A study of personal names and changes in name-giving patterns leads us to a better understanding of the culture and the socio-cultural values of different societies and ethnic groups. By studying people's choice of names we can understand what is important for them and this helps us appreciate other people's rights, preferences, feelings, ideas, and practices, what we believe is the purpose of 'intercultural studies'.

\section{References}

Aden, Etilia (2011). Naming your baby. Available online: http://www.babynamestats.com/

Alford, Richard D. (1987). Naming and Identity: A cross-cultural study of personal naming practices. New Haven, Connecticut: HRAF Press

Bloor, Meriel and Bloor, Thomas (2007). The Practice of Discourse Analysis. London: 
Hodder Arnold.

Bryner, Jeanna (2010). Parents Choosing More Unusual baby Names Now. Available Online: http://www.livescience.com/9841-parents-choosing-unusual-baby-names.html

Conrad, Linda (2010). Why Giving Personalized Baby Item Are Special-Different Culture's Traditions in Naming a Child. Available online: http://EzineArticles.com/?expert=linda_conrad

Deardorrff, D. K. (2004). In Bertselsmann, S. The key competence in the $21^{\text {st }}$ century? Available Online: http://www. Bertelsmannstiftung.de/bst/de/media/xcms_bst_dms_ 18255_18256_2.pdf

Djcnonyomaye, Fortune (2002). Names Have Special Meanings in Many African Countries. Silver International Newspaper. Available online: http://silverinternational.mbhs.edu/v161/v16.1.05b.africanname.htm

Encyclopedai of Children (2011). Naming. Encyclopedia of Children and Childhood in History and Society. Available online: http://www.faqs.org/childhood/MePa?Naming.html

Gardner, Sheena. (1988). Arabic Personal Names: their meanings and significance. In Linguistic Circle of Manitoba \& North Dakota, 28, 15-17.

Gardner, Sheena. (1992). Gender Imbalance in Sudanese Arabic Names. Paper presented at the annual meeting of the Canadian Society for the Study of Names. Charlottetown, PEI.

Gardner, Sheena. (1993). The nature and extent of religious significance of urban male names in northern Sudan. Paper presented at the International Congress of Onomastic Sciences, Trier.

Gerhards, Jurgen and Hans, Silke (2009). From Hasan to Herbert: Name-Giving Patterns of Immigrant Parents between Acculturation and Ethnic Maintenance. AJS. Vol: 114. No. 4. PP. $1102-28$

Ghaleb Al-Zumor, A. Q. (2009). A Socio-cultural and Linguistic Analysis Of Yemeni Arabic Personal Names. GEMA Online Journal of language Studies. Vol: 2.

Girvilas, K. A. (1978). PRE-CHIRISTIAN NAME GIVING IN LITHANIA. Lithuanian Quarterly Journal of Arts and Sciences. Vol: 24. No. 3. Available online: http://www.lithuanas.org/1978/78_3_02.htm

Gordon, Milton M. (1964). In Gerhards, T. and Hans, S. (2009). From Hasan to Herbert: Name-Giving Patterns of Immigrant Parents between Acculturation and Ethnic Maintenance. 
AJS. Vol: 114.No. 4. PP. 1102-28

Gurdun, Kavaran (2002). Icelandic Personal Names in Past and Present. Onoma. Vol: 37. PP. 293-300. DOI: 10.2143/ONO.37.0.519198.

Jeshion, Robin (2009). The Significance of Names. Mind \& Language. Vol:24. No.4.PP.372-405

Johnston, Barbara (2008). Discourse Analysis (2 ${ }^{\text {nd }}$ ed.). UK:Blackwell Publishing Ltd.

Liberson, Stanley In Gerhards, T. and Hans, S. (2009). From Hasan to Herbert: Name-Giving Patterns of Immigrant Parents between Acculturation and Ethic Maintenance. AJS. Vol: 114. No.4.PP.1102-28

Mayrand, Lionel E. (2011). The Origin and Meaning of Names. Available Online: http://www.mayrand.Org/meaning-e2.htm

Medlej, Youmane (2011). Issues of naming. Available Online: http://www.cedarseed.com/air/ namearticles2.html

Penbek, Sebnem et al, (2009). Intercultural Communication Competence: A Study about the Intercultural Sensitivity of University Students on Their Education and International Experiences. Paper presented at European and Mediterranean Conference on Information Systems. July, 12-14. Izmir

Rosenhouse, Judith (2002). Personal Names in Hebrew and Arabic: Modern Trends Compared to the Past. Journal of Semetic Studies.Vol: 7. No. 1. PP. 97-114

Sue, Christina A. and Telles, Edward E. (2007). Assimilation and Gender in Naming. American Journal of Sociology. Vol: 112. No. 5. PP. 1383-1415

Toppe, Ronald (2011). Norwegian Baby Names. Available online: http://bestnorwegian.com/norwegian_baby_names.html

Wang, YanJun and Le, Thao (2011). Teaching, learning and management: A case study of intercultural communication and education. Retrieved 2011. AARE 2006 Conference Proceedings, 27-30. November, Adelaide EJ ISSN 1324-9339 (2007) [Refereed Conference Paper]

Wardhaugh, Ronald (2006). An Introduction to Sociolinguistics (5 ${ }^{\text {th }}$ ed.). Uk:Balckwell Publishing Ltd.

Widdowson, H. G. (2007). Discourse Analysis. Oxford: Oxford University Press. 
Wikipedia, (2011). Given Name. Online: Retrieved in 2011 from http:en.wikipedia.org/wiki/Namegiving 